\title{
Suscetibilidade de três espécies cítricas à Dothiorella gregaria Sacc. em função do estado nutricional
}

\author{
Suscetibility of three citrus species to Dothiorella gregaria Sacc. in function of the nutriconal state
}

\author{
Wilson da Silva Moraes ${ }^{\mathrm{I}}$ Hilário Antônio de Castro ${ }^{\text {II }}$ Juliana Domingues Lima ${ }^{\text {III }}$ \\ Eloísa Aparecida das Graças Leite ${ }^{\mathrm{II}}$ Maurício de Souza ${ }^{\mathrm{IV}}$
}

\section{RESUMO}

\begin{abstract}
O comportamento da tangerineira "Ponkan", da tangoreira "Murcot" e da laranjeira "Valência" inoculadas artificialmente com dois isolados de Dothiorella gregaria foi avaliado sob diferentes épocas do ano, estados nutricionais e fenológicos. No período compreendido entre os meses de novembro a dezembro, em fase posterior à colheita dos frutos, as plantas mostraram-se mais afetadas pelos isolados do fungo. "Ponkan" mostrou-se mais afetada, seguida por "Murcot" $e$ "Valência", observando-se a mesma suscetibilidade das espécies nos diferentes períodos, porém com maior severidade da doença sob condições de elevada precipitação e umidade relativa. As plantas que apresentaram menores teores de Ca e Zn atingiram maiores índices de lesão, ocasião em que se encontravam em fase posterior à colheita. Os resultados indicam o efeito da época de inoculação na severidade da gomose causada por D. gregaria e confirmam a predisposição de plantas mais debilitadas nutricionalmente.
\end{abstract}

Palavras-chave: espécies cítricas, gomose, Botryosphaeria dothide, nutrição, predisposição.

\section{ABSTRACT}

The behavior of the mandarin 'Ponkan', tangor 'Murcot' and orange 'Valência', artificially inoculated with two isolates of the Dothiorella gregaria, was evaluated under different seasons of the year an under nutritional and phenological states. During the period between december and november, in a subsequent phase of harvesting of the fruits, the plants had showed more affected by the isolated fungus. 'Ponkan' revealed to be more affected, followed by 'Murcot' and 'Valencia'. The suscetibility of the species showed more severity of the disease under favorable conditions. The plants showing lower contents of $\mathrm{Ca}$ and $\mathrm{Zn}$ reached the highest rates of lesion, and they were in the subsequent phase of harvesting. The results indicated the effect of the inoculation time in the severity of gomosis caused by $\mathbf{D}$. gregaria and confirm the predisposition of the weakened plants nutritionaly.

Key words: citrus species, gummosis, Botryosphaeria dothide, nutrition, predisposition.

\section{INTRODUÇÃO}

Em tangoreira "Murcot”, um híbrido entre laranjeira e tangerineira, tem sido verificada uma gomose causando danos irreversíveis à produção e à longevidade das plantas, constituindo motivo de preocupação para citricultores e pesquisadores (RIBEIRO et al., 1975; WHITESIDE et al., 1988). Esta doença causada pelo fungo Botryosphaeria dothidea (Dothiorella gregaria) tem ocorrido em caráter epidêmico. Em cultivares suscetíveis de pêssego, estudos têm mostrado que esse tipo de gomose afeta o crescimento e a produção de frutos (BECKMAN et al., 2003).

D. gregaria é um parasita facultativo que ataca plantas subnutridas, encontrado, geralmente, associado aos tecidos mais debilitados ou quase mortos (WEAVER, 1979; WHITESIDE et al., 1988). Sua

\footnotetext{
'Laboratório de Sanidade Vegetal, Pólo Regional do Vale do Ribeira, Agência Paulista de Tecnologia dos Agronegócios (APTA), Registro, SP, Brasil. Email: wilson@aptaregional.sp.gov.br.

IDepartamento de Fitopatologia, Universidade Federal de Lavras (UFLA), CP 37, 37200-000, Lavras, MG, Brasil.

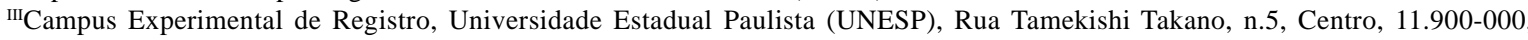

Registro, SP, Brasil. Email: judlima@registro.unesp.br. Autor para correspondência.

${ }^{\text {IV }}$ Departamento de Agricultura, UFLA, CP 37, 37200-000, Lavras, MG, Brasil.
} 
penetração dá-se principalmente por ferimentos ou aberturas naturais (NSOLOMO et al., 2000; MIRZAEE et al., 2002; VALENCIA-BOTÍN et al., 2003).

A suscetibilidade e a resistência das plantas às doenças são controladas por fatores genéticos e a condição de maior ou menor suscetibilidade é determinada por fatores não-genéticos como a idade da planta e o ambiente, os quais freqüentemente atuam antes da infecção pelo patógeno (BENDENDO, 1995; SMITH, et al., 1996; ROUX \& WINGFIELD, 1997).

Além da elevada densidade do hospedeiro suscetível, é importante que, na fase crítica em que a epidemia vá se estabelecer, o hospedeiro apresente-se propenso a contrair a doença. Caracteres morfológicos, idade e estado nutricional das plantas, ou fatores do ambiente e práticas culturais podem alterar a suscetibilidade (KRÜGNER \& BACCHI, 1995; BENDENDO, 1995; LUQUE et al., 2002). Queimaduras do sol, injúrias, ferimentos, infecções prévias determinadas por outros organismos, aplicações de pesticidas, condições ambientais desfavoráveis ou outros fatores debilitantes podem ser condições necessárias ao desenvolvimento e proliferação da doença (AVERNA-SACCÁ, 1938; SALZEDAS \& NETO, 1985; WHITESIDE etal., 1988; FERREIRA, 1989; KRÜGNER \& BACCHI, 1995; SÁNCHEZHERNÁNDEZ et al., 2002).

Os objetivos do presente estudo foram: avaliar o efeito da época de inoculação na suscetibilidade de laranjeira "Valência”, tangerineira "Ponkan" e tangoreira "Murcot”, quando inoculadas artificialmente com o fungo $\boldsymbol{D}$. gregaria; determinar a relação entre o estado nutricional das plantas e a severidade da doença nestas espécies; verificar a relação entre o estado fenológico das plantas e a severidade da doença; e avaliar isolados do fungo de diferentes procedências.

\section{MATERIAL E MÉTODOS}

Dois ensaios foram implantados e conduzidos no pomar da Universidade Federal de Lavras (UFLA), em Lavras, Minas Gerais, em dois períodos: setembro a outubro e novembro e dezembro. Nos ensaios, foram utilizadas árvores de tangerineira "Ponkan" e laranjeira "Valência" em bom estado de vigor e sanidade. No caso de tangoreira "Murcot", todas as árvores estavam naturalmente infectadas, exibindo lesões necróticas nos troncos e ramos.

No ensaio I, as inoculações artificiais foram feitas no primeiro dia do mês de setembro e as avaliações durante os meses de setembro e outubro. No ensaio II, as inoculações foram feitas no primeiro dia do mês de novembro e as avaliações durante os meses de novembro e dezembro.

Dois isolados do fungo D. gregaria foram utilizados nas inoculações artificiais, sendo o Isolado 1 (W1), coletado na UFLA, e o Isolado 2 (W2), na Fazenda Vitória, em Alfenas, MG. O isolamento foi feito por adaptação do método de indução de crescimento micelial (FERNANDEZ, 1993). Para tal, fragmentos da casca lesionada de troncos de árvores naturalmente infectadas de tangor "Murcot", com idades entre 10 e 14 anos, passaram por processo de assepsia e desinfestação superficial. Em seguida, parte do inóculo foi removido da casca, plaqueado em meio BDA, e posteriormente incubado a $25 \pm 2^{\circ} \mathrm{C}$ por cinco dias. A multiplicação do inóculo foi feita pela repicagem de discos de micélio para meio BDA obtendo-se o inóculo inicial para as inoculações.

Em cada árvore, foram selecionados três ramos laterais, com diâmetros em torno de 3 a $6 \mathrm{~cm}$, localizados logo acima da forquilha da árvore e posicionados a uma altura de 80 a $120 \mathrm{~cm}$. Cada ramo foi inoculado com um dos isolados do fungo, restando um para a inoculação da testemunha. Em cada ramo, foram feitas cinco inoculações na superfície inferior, distantes em torno de $15 \mathrm{~cm}$ uma da outra, com o primeiro ponto de inoculação situado a $20 \mathrm{~cm}$ da forquilha.

Definidos os pontos de inoculação, um disco de casca com $1 \mathrm{~cm}$ de diâmetro foi removido, colocando-se, em seguida, um disco de igual diâmetro de meio de cultura BDA com micélio do fungo, posicionado com a face contendo o micélio voltado para o lenho. A testemunha recebeu apenas disco de meio de cultura BDA. Posteriormente, os pontos de introdução do inóculo foram protegidos com fita plástica. Esta técnica de inoculação foi adaptada de RIBEIRO et al., (1975) e HOMECHIN \& KRÜGNER (1980).

Os tratamentos foram dispostos no delineamento inteiramente casualizado em parcelas subdivididas com oito repetições, tendo na parcela as três espécies cítricas, cada uma constituída de três ramos com cinco pontos inoculados, e na sub-parcela dois isolados do fungo e a testemunha.

Os ensaios foram avaliados semanalmente por 56 dias, sendo feitas medidas do comprimento e da largura das lesões e determinado um índice de lesão (IL), pelo produto do comprimento e largura de cada lesão produzida. Durante os ensaios, também foi observado o estado fenológico das plantas e os dados meteorológicos registrados diariamente. Adicionalmente, foram feitas duas coletas mensais para diagnose foliar nas plantas submetidas às inoculações nos dois ensaios, sendo feitas 24 amostragens em cada 
coleta, oito plantas para cada uma das espécies cítricas. Os teores de $\mathrm{N}$ total foram determinados pelo método semi-micro-Kjedahl, segundo LIAO (1981), e a destilação e titulação, segundo BREMNER \& EDWARDS (1965). No extrato obtido por digestão nítrico-perclórica (ZAROSKI \& BURAU, 1977), foram dosados os teores de P por colorimetria, os de $\mathrm{Ca}, \mathrm{Mg}$, $\mathrm{Cu}, \mathrm{Fe}, \mathrm{Mn}$ e Zn por espectrofotometria de absorção atômica, os de K por fotometria de emissão de chama e os de S total por turbidimetria (BLANCHAR et al., 1965). O teor de B foi determinado por incineração, e a determinação, no extrato, pelo método da azometina por colorimetria (GUPTA, 1979).

Para cada isolado e cada espécie cítrica, efetuou-se o reisolamento do fungo das áreas lesionadas pelo mesmo processo descrito anteriormente, sendo a identificação baseada em características morfológicas e reprodutivas em meio de cultura BDA.

A análise de variância foi feita com base nos testes de normalidade, e os índices de lesão (IL) foram transformados por $\sqrt{X+1}$, em que X é o IL. As médias dos tratamentos foram comparadas pelo teste Tukey em nível de 5\% de probabilidade de erro. As correlações entre os IL e os teores de nutrientes foliares foram realizadas pelo método de Pearson, usando-se o teste t no programa SAEG.

\section{RESULTADOS E DISCUSSÃO}

No ensaio I, registrou-se temperatura média máxima de $30,43^{\circ} \mathrm{C}$, temperatura média mínima de $11,51^{\circ} \mathrm{C}$, precipitação acumulada de $147,40 \mathrm{~mm}$ e umidade relativa média do ar de 58,35\% (Figura 1). No período de setembro a outubro, as três espécies cítricas estavam em floração, enquanto que "Ponkan” em colheita ou em fase posterior à colheita de frutos, "Murcot" em colheita e "Valência” em pré-colheita.

No ensaio II, registrou-se temperatura média máxima de $30,89^{\circ} \mathrm{C}$, temperatura média mínima de $15,55^{\circ} \mathrm{C}$, precipitação acumulada de $442 \mathrm{~mm}$ e umidade relativa média do ar em torno de 74,42\% (Figura 1). No período de novembro a dezembro, "Ponkan” e "Murcot" estavam em fase posterior à colheita e "Valência” em fase final de colheita.

De modo geral, a ordem decrescente de suscetibilidade verificada em "Ponkan", "Murcot" e "Valência” mostrou-se diferente em função das épocas do ano, mantendo as mesmas proporções em ambos os ensaios (Tabela 1). No ensaio I, avaliado de setembro e outubro, "Ponkan” apresentou IL final de $4,89 \mathrm{~cm}^{2}$, "Murcot” IL de 3,64cm², não diferindo entre si, e "Valência” IL de $0,80 \mathrm{~cm}^{2}$ (Tabela 1). No ensaio II, conduzido nos meses de novembro e dezembro, "Ponkan" apresentou o maior IL, seguida de "Murcot" e, "Valência” que apresentaram IL próximos (Tabela 1).

Os resultados indicam que a suscetibilidade verificada no ensaio I ocorreu nas mesmas proporções daquela observada no ensaio II. Entretanto, a severidade da doença mostrou maior intensidade no ensaio II. Isso sugere que fatores do clima observados no segundo período, especialmente a precipitação e a umidade relativa, contribuíram para a elevação dos índices de lesão obtidos nas espécies. As temperaturas medidas nos períodos apresentaram-se dentro das exigidas para o desenvolvimento favorável do patógeno, conforme observações de WEAVER (1979). Os índices médios de lesão de 2,79 e $19,01 \mathrm{~cm}^{2}$, obtidos, respectivamente, para os ensaios I e II, foram diferentes (Tabela 1). A partir deste resultado, pode-se inferir que, entre os períodos estudados, o mais favorável para o desenvolvimento da doença correspondeu ao do ensaio II. O efeito da época de inoculação parece mais evidente no período compreendido entre os meses de novembro e dezembro, no qual se observou nível mais elevado de precipitação e umidade relativa (Figura 1). É provável que estes fatores do clima tenham contribuído para um maior desenvolvimento das lesões no ensaio II e para o retardamento no desenvolvimento das lesões no ensaio I. Em pêssego, foram observadas correlações positivas entre umidade relativa, precipitação e severidade da doença (PUSEY \& BERTRAND, 1993).

Nos dois ensaios, não foram observadas diferenças significativas entre os IL dos isolados inoculados, W1 e W2, indicando não haver diferenças quanto à agressividade destes isolados de diferentes procedências nos dois períodos estudados (Tabela 1). Também não foram observadas diferenças nas características morfológicas dos isolados crescendo em meio de cultura BDA.

O requerimento nutricional da planta varia com os diferentes estádios fenológicos (RODRIGUEZ, 1991). As evidências mostraram que $\boldsymbol{D}$. gregaria é um parasita fraco em plantas cítricas, preferindo plantas desnutridas. Nas condições do ensaio I, por exemplo, plantas com teores baixos de N, P, K, Ca, Cu e Zn apresentaram maior índice de lesão (Tabela 2). Nas condições do ensaio II, plantas com teores normais apenas de $\mathrm{P}, \mathrm{K}$ e Mn apresentam um maior índice de lesão (Tabela 2). Isso pode ser atribuído provavelmente à insuficiência nos teores de $\mathrm{N}, \mathrm{Ca}, \mathrm{Cu}$ e $\mathrm{Zn}$ em associação aos demais nutrientes, o que também foi observado em plantas do ensaio I, o que confere maior resistência ao patógeno. Ainda neste período, observou-se que plantas com teores normais de Ca, 


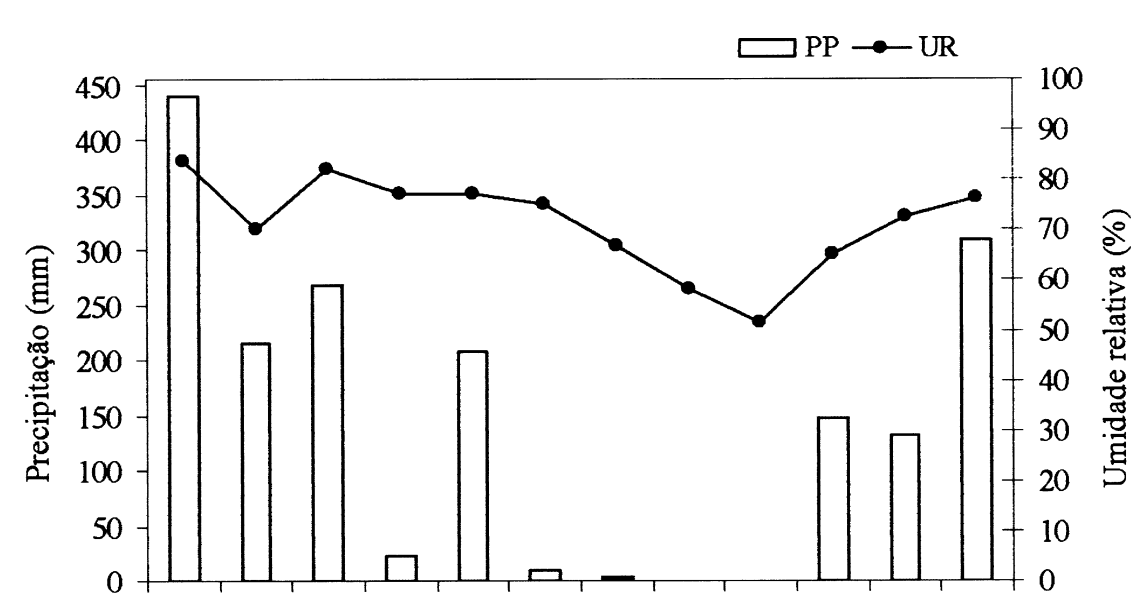

Jan Fev Mar Abr Mai Jun Jul Ago Set Out Nov Dez

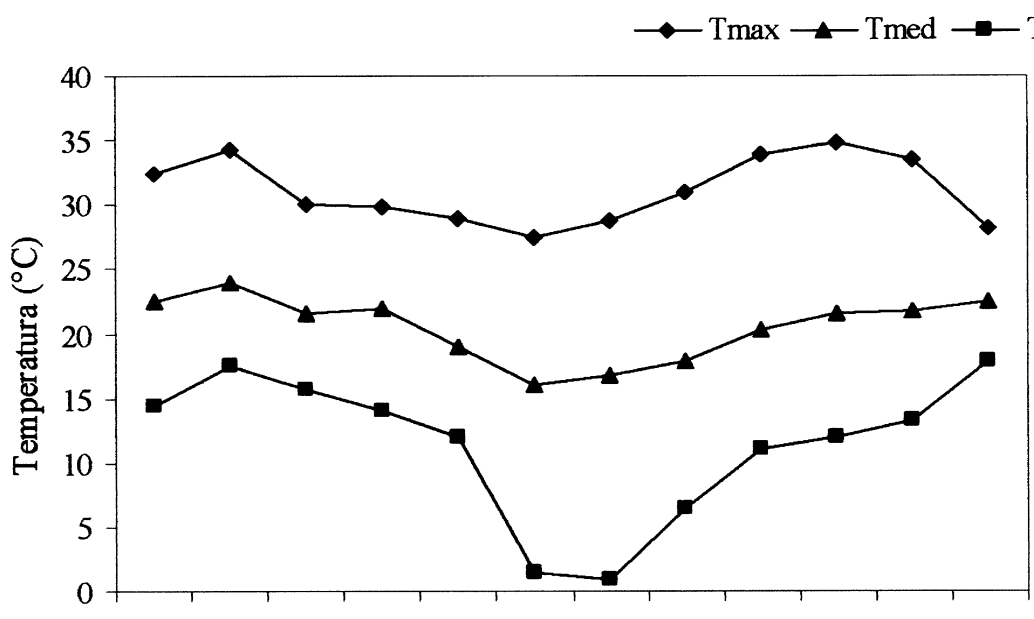

Jan Fev Mar Abr Mai Jun Jul Ago Set Out Nov Dez

Figura 1 - Elementos do clima: precipitação (PP), umidade relativa (UR) e temperaturas máxima, média e mínima $\left({ }^{\circ} \mathrm{C}\right)$ mensais obtidas por determinações diárias na Estação Climatológica da UFLA, Lavras, MG.

Mg, Zn e Fe apresentaram menor índice de lesão e vice-versa (Tabela 2).

As interações das informações obtidas nos ensaios sugerem que plantas com baixos teores de Ca e Zn mostraram-se mais suscetíveis ao patógeno, enquanto teores extremos de $\mathrm{P}$ e $\mathrm{K}$ promoveram um maior ou menor índice de lesão. Acredita-se com isso que a suplementação de N, Ca e $\mathrm{Zn}$ de forma balanceada possa reduzir consideravelmente a severidade da doença. Pomares que se mostrarem severamente afetados pela doença podem estar indicando a necessidade de adubação equilibrada, ou mesmo da reposição de nutrientes que são exportados em maior quantidade por ocasião da colheita dos frutos, como N e Ca (RODRIGUEZ, 1991; FAQUIM, 1994).

Plantas em fase posterior à colheita foram mais severamente afetadas pelo patógeno. Durante o ensaio I, as plantas de tangerina "Ponkan” atingiram índice de lesão máximo de 4,89cm² (Tabela 1), estando em fase posterior à colheita, quando os teores de nutrientes mostraram-se reduzidos, devido à exportação pelos frutos na colheita. No entanto, as condições de clima, particularmente, a precipitação e a umidade relativa, foram mais baixas neste período, contribuindo certamente para um menor IL, em relação a 29,15 $\mathrm{cm}^{2}$, conforme observado no ensaio II (Tabela1). Paralelamente a isto, um menor IL foi observado nas demais espécies.

Ciência Rural, v.37, n.1, jan-fev, 2007. 
Tabela 1 - Médias dos índices de lesão (IL) $\left(\mathrm{cm}^{2}\right)$ em ramos de espécies cítricas inoculados com dois isolados de $\boldsymbol{D}$. gregaria de diferentes procedências, em duas épocas diferentes, medidos aos 56 dias após as inoculações.

\begin{tabular}{lcccc}
\hline \multicolumn{5}{c}{ Ensaio I - 01/09 a 27/10 } \\
\hline Isolados & Ponkan & Murcot & Valência & Médias \\
W-1 & $5,34 \mathrm{a}$ & $3,52 \mathrm{a}$ & $0,85 \mathrm{a}$ & $2,90 \mathrm{a}$ \\
W-2 & $4,46 \mathrm{a}$ & $3,77 \mathrm{a}$ & $0,74 \mathrm{a}$ & $2,69 \mathrm{a}$ \\
Médias & $4,89 \mathrm{a}$ & $3,64 \mathrm{a}$ & $0,80 \mathrm{~b}$ & $2,79 \mathrm{a}$ \\
& & & \\
& & & \\
Isolados & Ponkan & Murcot & Valência & Médias \\
W-1 & $27,92 \mathrm{a}$ & $16,72 \mathrm{~b}$ & $12,11 \mathrm{~b}$ & $19,53 \mathrm{a}$ \\
W-2 & $30,40 \mathrm{a}$ & $15,11 \mathrm{~b}$ & $14,88 \mathrm{~b}$ & $18,49 \mathrm{a}$ \\
Médias & $29,15 \mathrm{a}$ & $15,93 \mathrm{~b}$ & $13,46 \mathrm{~b}$ & $19,01 \mathrm{a}$ \\
\hline
\end{tabular}

Médias de oito repetições provenientes de cinco pontos inoculados por árvore por repetição.

Médias seguidas por letras distintas, na linha e na coluna, diferem entre si em nível de significância de 5\% pelo teste Tukey.

As plantas em estádio de colheita, no caso de "Murcot", apresentaram nível intermediário de suscetibilidade (IL de 3,64cm²), e plantas em précolheita, como a "Valência", atingiram menor IL $\left(0,80 \mathrm{~cm}^{2}\right)$ durante o ensaio I (Tabela 1$)$. Verificou-se, com isto, que plantas de "Murcot”, por encontraremse em fase de colheita, mostraram suscetibilidade intermediária entre "Ponkan" e "Valência”, embora estatisticamente semelhante à da primeira. Da mesma forma, "Valência" mostrou-se menos suscetível,

Tabela 2 - Coeficiente de correlação de Pearson (r) entre os índices de lesão (IL) causado por $\boldsymbol{D}$. gregaria em espécies cítricas e os teores de macro e micronutrientes obtidos em análises foliares no ensaio I (1/9 a 27/10) e no ensaio II (01/11 a 27/12).

\begin{tabular}{lcll}
\hline Variável & Variável & Ensaio I r & Ensaio II r \\
\hline IL & Nn & $-0,3274$ & $-0,0773 n s$ \\
IL & Pn & $-0,4657^{*}$ & $+0,6900^{*}$ \\
IL & $\mathrm{Kn}$ & $-0,3144^{*}$ & $+0,8036^{*}$ \\
IL & $\mathrm{Ca}$ & $-0,2948^{*}$ & $-0,3443^{*}$ \\
IL & $\mathrm{Mg}$ & $+0,0670^{*}$ & $-0,4346^{*}$ \\
IL & $\mathrm{Sn}$ & $-0,1591 \mathrm{~ns}$ & $-0,1039 \mathrm{~ns}$ \\
IL & $\mathrm{Bn}$ & $-0,1722 \mathrm{~ns}$ & $+0,0313 \mathrm{~ns}$ \\
IL & $\mathrm{Cu}$ & $-0,2917 *$ & $+0,2079 \mathrm{~ns}$ \\
IL & $\mathrm{Mn}$ & $-0,0596 \mathrm{~ns}$ & $+0,2937 *$ \\
IL & $\mathrm{Zn}$ & $-0,4113^{*}$ & $-0,3866^{*}$ \\
IL & $\mathrm{Fe}$ & $-0,2276 \mathrm{~ns}$ & $-0,4378^{*}$ \\
\hline
\end{tabular}

Médias de nutrientes provenientes de 48 observações de análises foliares realizadas, no ensaio I, nos dias 15/09/ e 15/10, e, no ensaio II, nos dias 15/11 e 15/12.

*Significativo a $5 \%$ de probabilidade de erro.

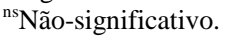

provavelmente por encontrar-se em fase de précolheita.

No ensaio II, no qual houve precipitação e umidade relativa mais elevadas (Figura 1), as plantas retomaram o crescimento com emissão de brotações novas. "Ponkan" e "Murcot" encontravam-se em fase de pós-colheita e pós-floração e "Valência" em plena colheita e pós-colheita. Com isso, "Valência" atingiu IL mais altos do que no ensaio I, a ponto de igualar-se à "Murcot" em suscetibilidade (Tabela 1).

Assim, o comportamento das espécies cítricas em termos de suscetibilidade variou de acordo com a época do ano e o estado nutricional das plantas. Em ordem decrescente de suscetibilidade, "Ponkan”, "Murcot” e "Valência” mostraram-se afetadas em função de encontrarem-se em fase posterior à colheita, colheita e pré-colheita de frutos por ocasião do ensaio I, e em fase posterior à colheita, durante o ensaio II, respectivamente. A maior suscetibilidade apresentada pelas plantas, quando inoculadas artificialmente com $\boldsymbol{D}$. gregaria, foi observada no ensaio II, período em que as condições climáticas foram favoráveis ao desenvolvimento do patógeno e quando as plantas estavam nutricionalmente mais esgotadas, ou seja, em fase posterior à colheita (Tabela 1).

Numa outra visão, as características vegetativas das espécies estudadas podem condicionar um maior ou menor desenvolvimento das lesões, propiciando ambiente favorável ao patógeno ou a doença. "Ponkan” possui uma copa bem desenvolvida, mais ramificada e fechada, "Murcot" copa menos ramificada e mais aberta, enquanto que Valência possui copa menos desenvolvida, com ramos menores. Essas características parecem indicar maior requerimento nutricional pelas plantas mais desenvolvidas e favorecimento de um microclima sob a copa, pela redução da insolação e da aeração.

\section{CONCLUSÃO}

Os resultados indicam o efeito da época de inoculação na severidade da gomose causada por $\boldsymbol{D}$. gregaria e confirmam a predisposição de plantas mais debilitadas nutricionalmente a esta doença.

\section{REFERÊNCIAS}

AVERNA-SACCÁ, R. Contribuição para o estudo das doenças criptogâmicas das plantas cítricas: uma gomose produzida por Dothiorella. Revista de Agricultura, São Paulo, v.13, p.107126, 1938. 
BECKMAN, T.G. et al. Impact of fungal gummosis on peach trees. Hortscience, Alexandria, v.3, n.6, p.1141-1143, 2003.

BENDENDO, I.P. Ambiente e doença. In: BERGAMIN FILHO, A.; et al. (Eds). Manual de fitopatologia: princípios e conceitos. 3.ed. São Paulo: CERES, 1995. v.1.

BLACHAR, R.W. et al. Sulfur in plant material digestion with nitric and perchloric acids. Soil Science Society of America Proceedings, Madison, v.29, n.1, p.71-72, 1965.

BREMNER, J.M.; EDWARDS, H.L. Determination and isotope ratio analysis of differents forms of nitrogen in soils. I. Aparatus and procedures for destillation and determination for ammonium. Soil Science Society of America Proceedings, Madison, v.29, n.1, p.504-507, 1965.

FAQUIM, V. Nutrição mineral de plantas. Lavras: ESALFAEP, 1994. 227p.

FERNANDEZ, M.R. Manual para laboratório de fitopatologia. Passo Fundo: Centro Nacional de Pesquisa do Trigo-EMBRAPA, 1993. 128p.

FERREIRA, F.A. Patologia florestal: principais doenças florestais no Brasil. Viçosa: Sociedade de Investigações Florestais, 1989. 570p.

GUPTA, U.C. Some factors affecting the determination of hot-water soluble boron from podzol soils using azomethine. Canadian Journal of Soil Science, Ottawa, v.59, p.241247, 1979.

HOMECHIM, M.; KRÜGNER, T.L. Avaliação da patogenicidade de isolados de Cylindrocladium clavatum Hodges \& May em árvores de Pinus caribea Morelet var hondurensis Barret \& Golfari e $\boldsymbol{P}$. oocarpa Shiede. Summa Phytopatologica, Piracicaba, v.6, n.3-4, p.107-115, 1980.

KRÜGNER, T.L.; BACCHI, L.M.A. Fungos. In: BERGAMIN FILHO, A. et al. (Eds). Manual de fitopatologia: princípios e conceitos. 3.ed. São Paulo: Ceres, 1995. v.1.

LIAO, C.F.H. Devard"s alloy method for total nitrogen determination. Soil Science Society of American Journal, Madison, v.45, n.5, p.852-855, 1981.

LUQUE, J. et al. Seasonal changes in susceptibility of Quercus suber to Botryosphaeria stevensii and Phytophthora cinnamomi. Plant Pathology, Oxford, v.51, p.338-345, 2002.

MIRZAEE, M.R. et al. Nattrassia mangiferae, the cause of die-back and trunk cankers of Ficus religiosa and branch wilt of
Psidium guajava in Iran. Journal of Phytopathology, Berlin, v.150, p.244-247, 2002.

NSOLOMO, V.R. et al. The ability of some fungi to cause decay in the East African camphor tree, Ocotea usambarensis. Mycology Research, v.104, n.12, p.1473-1479, 2000.

PUSAY, P.L.; BERTRAND, P.F. Seasonal infection of nonwounded peach bark Botryosphaeria dothidea. Phytopathology, Saint Paul, v.83, n.8, p.825-829, 1993.

RIBEIRO, I.J.A. et al. Ocorrência de Dothiorella sp. sobre tangor Murcote. Summa Phytopathologica, Piracicaba, v.1, n.4, p.303-304, 1975.

RODRIGUEZ, O. Aspectos fisiológicos, nutrição e adubação dos citros. In: RODRIGUEZ, O. et al. (eds). Citricultura brasileira. Campinas: Fundação Cargill, 1991. v.1, p.419475 .

ROUX, J.; WINGFIELD, M.J. Survey and virulence of fungi occurring on diseased Acacia mearnsii in South Africa. Forest Ecology and Management, Amsterdam, v.99, p.327-336, 1997.

SALZEDAS, L.F.; NETO, S.M.R. Ocorrência do cancro da goiabeira (Botryosphaeria dothidea [Muug ex Fr.] CES \& DE NOT.) na região de Araçatuba, Estado de São Paulo. O Biológico, São Paulo, v.51, n.11, p.295-297, 1985.

SÁNCHEZ-HERNÁNDEZ, M.E. et al. Botryosphaeria canker of Cistus ladanifer. Plant Pathology, Oxford, v.51, p.365373, 2002.

SMITH, H. et al. Botryosphaeria dothidea endophytic in Eucalyptus grandis and Eucalyptus nitens in South Africa. Forest Ecology and Management, Amsterdam, v.89, p.189-195, 1996.

VALENCIA-BOTÍN, A.J. et al. Botryosphaeria dothidea causing stem spots on Hylocereus undatus in Mexico. Plant Pathology, Oxford, v.52, p.803, 2003.

ZAROSKI, R.J.; BURAU, R.G. A rapid nitric perchloric acid digestion method to mult-element tissue analysis. Communication in Soil Science and Plant Analysis, New York, v.8, n.5, p.425-436, 1977.

WEAVER, D.J. Role of conidia of Botryosphaeria dothidea in the natural spread of peach gummosis. Phytopathology, Saint Paul, v.69, n.4, p.330-334, 1979.

WHITESIDE, J.O. et al. Compendium of citrus disease. Flórida: APS, 1988. 80p. 